Article

\title{
Visualizing the Knowledge Structure and Research Evolution of Infrared Detection Technology Studies
}

\author{
Rui Hong ${ }^{1}$, Chenglang Xiang ${ }^{1}$, Hui Liu ${ }^{1} * \mathbb{C}$, Adam Glowacz ${ }^{2}\left(\mathbb{D}\right.$ and Wei Pan ${ }^{3}$ \\ College of Quality and Safety Engineering, China Jiliang University, Hangzhou 310018, China \\ 2 Faculty of Electrical Engineering, Automatics, Computer Science and Biomedical Engineering, \\ AGH University of Science and Technology, Al. A. Mickiewicza 30, 30-059 Krakow, Poland \\ 3 School of Resource and Safety Engineering, Central South University, Changsha 410083, China \\ * Correspondence: liuhui2003@126.com; Tel.: +86-571-869-14534
}

Received: 15 May 2019; Accepted: 27 June 2019; Published: 1 July 2019

\begin{abstract}
This paper aims to explore the current status, research trends and hotspots related to the field of infrared detection technology through bibliometric analysis and visualization techniques based on the Science Citation Index Expanded (SCIE) and Social Sciences Citation Index (SSCI) articles published between 1990 and 2018 using the VOSviewer and Citespace software tools. Based on our analysis, we first present the spatiotemporal distribution of the literature related to infrared detection technology, including annual publications, origin country/region, main research organization, and source publications. Then, we report the main subject categories involved in infrared detection technology. Furthermore, we adopt literature cocitation, author cocitation, keyword co-occurrence and timeline visualization analyses to visually explore the research fronts and trends, and present the evolution of infrared detection technology research. The results show that China, the USA and Italy are the three most active countries in infrared detection technology research and that the Centre National de la Recherche Scientifique has the largest number of publications among related organizations. The most prominent research hotspots in the past five years are vibration thermal imaging, pulse thermal imaging, photonic crystals, skin temperature, remote sensing technology, and detection of delamination defects in concrete. The trend of future research on infrared detection technology is from qualitative to quantitative research development, engineering application research and infrared detection technology combined with other detection techniques. The proposed approach based on the scientific knowledge graph analysis can be used to establish reference information and a research basis for application and development of methods in the domain of infrared detection technology studies.
\end{abstract}

Keywords: infrared detection technology; research evolution; bibliometric; visualization; scientific knowledge graph

\section{Introduction}

Infrared detection technology refers to the difference in heat transfer caused by defects or internal structural defects on the surface of the measured object, which may cause differences in object surface temperature. The nondestructive testing method detects surface and internal structural defects of an object by displaying the difference through infrared thermal imaging technology. The main instrument is the thermal imaging camera, which uses two different methods: passive and active [1]. In passive thermal imaging cameras, radiation from a target object is measured without any external thermal stimulus. On the other hand, an active thermal imaging camera is an object whose temperature is measured after a period of delay once a sample is subjected to external thermal stimulation $[2,3]$. Compared with the conventional nondestructive testing technology, infrared detection technology has 
many advantages such as fast detection speed, noncontact, wide adaptability, wide temperature range, easy automation and real-time observation [4].

The intensity of the infrared radiation emitted by the object is mainly a function of temperature. The higher is the temperature, the greater is the emitted infrared energy intensity [5]. This feature can be exploited by many different applications. For example, the positioning of mobile robots in smart spaces [6]. Infrared detection technology was originally used for military purposes, but it has since been widely used in aerospace, agriculture, civil engineering, medicine, and veterinary applications [7]. In the aerospace field, thermal imaging cameras are widely used to detect large aerospace components such as helicopter aircraft, helicopter primary and secondary structures, aero-engine components, spacecraft components and their subsystems [8]. In the medical field, the temperature is a good indicator of health, as several changes in the skin can be used as indicators of possible illness [9]. Therefore, thermal imaging cameras can be used as an alternative diagnostic tool in medical applications. For example, thermal imaging cameras are used to detect tumors on the body surface, such as breast cancer $[10,11]$. In addition, infrared imaging technology is used in many other medical applications, such as the diagnosis of diabetic neuropathy or vascular disease [12], fever screening [13], skin disease [14] and cardiac surgery [15]. In the field of mechanical testing, infrared thermal imaging is a good detection technology, especially for power production, mechanical maintenance testing, and process monitoring. Examples include electrical equipment inspection [16], plastic deformation monitoring [17] and other condition monitoring applications [18]. Tensile deformation testing [19], material fatigue damage assessment [20], mechanical diagnosis [21,22], and weld inspection [23] can effectively reduce costs, and improve production and safety during inspection. In addition, due to its fast thermal imaging, large measurement range and intuitive features, infrared detection technology is suitable for construction. The temperature distribution on the facade of a building provides very useful information on many hidden conditions related to building performance and maintenance [24]. For example, it can be used to detect defects in building structures, energy leaks, and water penetration and moisture $[25,26]$.

It can be seen that infrared detection technology has achieved quite good results in individual fields, but continuous research and experiments are needed to improve the theory, technology and products. To better understand the application and development of infrared detection technology in various fields, based on the WOS core database from 1990 to 2018, we select information visualization analysis software VOSviewer and Citespace, and using the bibliometric analysis method, the development process and structural relationship of infrared detection technology are displayed in the visualization method and scientific knowledge graph. From the perspective of multivariate dynamic time-sharing of the infrared detection technology, literature information mining is carried out, and the basic theory, research theme and frontier are analyzed. The purpose is to clarify the hotspot changes and future trends of infrared detection technology research. The time, spatial distribution and hotspots of infrared detection technology research literature are discussed and analyzed.

\section{Data and Methods}

\subsection{Data Source}

In this paper, we have comprehensively searched the international literature on infrared detection technology, covering a timespan of 1990-2018, from the Web of Science (WOS) core collection by advanced searching: "TS $=\left(\right.$ "infrared thermography" OR "infrared thermal") AND TS $=\left(\right.$ detect $\left.{ }^{*}\right)$ ". Through screening, there are 1614 documents from 46 countries or regions, 1746 research organizations, 674 journals and 5476 authors. Eight document types were found in these 1614 documents, as shown in Table 1. The proportion of articles is as high as $93.247 \%$, followed by conference papers and reviews, accounting for $7.187 \%$ and $5.328 \%$, respectively. In addition, the total number of documents in Table 1 is 1731, and the total number is larger than the search results. This is because a document may be repeatedly identified as different type. 
Table 1. Type of documents.

\begin{tabular}{cccc}
\hline Rank & Type of Document & Frequency & Proportion \\
\hline 1 & Article & 1505 & 93.247 \\
\hline 2 & Proceedings paper & 116 & 7.187 \\
\hline 3 & Review & 86 & 5.328 \\
\hline 4 & Meeting abstract & 17 & 1.053 \\
\hline 5 & Correction & 2 & 0.124 \\
\hline 6 & Editorial material & 2 & 0.124 \\
\hline 7 & Letter & 2 & 0.124 \\
\hline 8 & Book Review & 1 & 0.062 \\
\hline Total & & 1731 & \\
\hline
\end{tabular}

\subsection{Methods and Tools}

With the rapid development of the informational world, to study the theoretical development, research methods or hot topics of a subject and identify the knowledge structure, scholars analyze by visualizing subject knowledge, and the main means is to draw a scientific knowledge graph of the literature data information.

This study used the information published in the WOS database to analyze the statistical publication time, source country/region, research organization, research direction, publication, author, h-index value and total citation frequency and to export the results for charting and analysis. The VOSviewer software is used to draw the national cohesive network density knowledge map of the research literature on infrared detection technology, the research organization coauthored knowledge map, the published citation knowledge map, the author's cocited knowledge map, and the keyword coexisting knowledge map. Citespace software was used to draw the keyword timeline view and analyze using bibliometric methods.

VOSviewer is a document knowledge unit visualization software based on VOS technology developed by Van Eck and Waltman of Leiden University in the Netherlands. It has unique advantages in displaying mapping knowledge, especially in clustering [27]. Citespace V software is a commonly used information visualization software developed by Chen Chaomei of Drexel University in the United States [28]. The current research hotspots, frontiers and trends are explored mainly through the scientific knowledge graph.

\subsection{Mathematical Model}

Van Eck and Waltman [29] proposed a new method for node similarity visualization. Establish $n$ n-type co-occurrence matrices and define the similarity matrix $S$ :

$$
S=\left(S_{i j}\right)
$$

where $S_{i j} \geq 0$ is a similarity measure defined below, and $S_{i j}=S_{j i}, i, j \in\{1,2, \cdots, n\}$. The similarity between two nodes $i$, and $j$ is represented by the similarity matrix $S_{i j}$. It shows that the higher is the degree of familiarity, the stronger is the connection between the two nodes.

The correlation strength method to calculate the similarity $S_{i j}$ between nodes $i$ and $j$ used VOSviewer as follows:

$$
S_{i j}=\frac{C_{i j}}{W_{i} W_{j}}
$$

where $C_{i j}$ represents the number of simultaneous occurrences of nodes $i$ and $j$, and $W_{i}$ and $W_{j}$ represent the total number of occurrences of nodes $i$ and $j$, respectively, or the total number of co-occurrences of these nodes. 
To make the effect of clustering more obvious, the link strength of the node should be as accurate as possible. Nodes with high correlation strength should be close to each other, and nodes with low correlation strength should be away from each other. The main idea of VOS is to minimize the sum of the weighted Euclidean distances of all objects in each cluster. In mathematical notation, the minimized objective function is as follows:

$$
E(X ; S)=\sum_{i<j} S_{i j}\left\|X_{i}-X_{j}\right\|^{2}
$$

Among them, $\|\cdot\|$ is a European norm. To avoid the appearance of two or more similar nodes in the same coordinates, use the following constraints:

$$
\sum_{i<j}\left\|X_{i}-X_{j}\right\|=1
$$

In summary, the similarity matrix can be used to construct the node coordinates to draw a visual knowledge network.

In addition, in the density knowledge map, the color of the nodes is determined by the dot density, and the average distance between the two points is represented by the distance $d$ as follows:

$$
d=\frac{2}{n(n-1)} \sum_{i<j}\left\|X_{i}-X_{j}\right\|
$$

$D(X)$ represents the density of the node $X\left(x_{i}, x_{j}\right)$ obtained by the following formula:

$$
D(X)=\sum_{i<j}^{n} W_{i} k\left\{\frac{\left\|X_{i}-X_{j}\right\|}{d h}\right\}
$$

where $k \in[0, \infty)$, represents the kernel function; $h>0$, represents the core width parameter; and $W_{i}$ represents the weight of node $i$, that is, the total frequency of node $i$ occurrence. The Gaussian kernel function used in VOS is:

$$
k(t)=e^{-t^{2}}
$$

After calculating the node density, the weighted average of the object colors in the cluster is calculated to obtain the cluster color, and the weight of one color is equal to the object density of the corresponding cluster. The resulting color is then blended with the background color of the cluster density view, which is typically black or white. The color of the nodes in the map can be obtained.

\section{Results and Discussion}

\subsection{Temporal Distribution of the Literature}

To analyze the research trends for infrared detection technology, the relevant annual publication volume data were extracted from the 1990 to 2018 WOS data, and the number of publications, h-index value and articles were drawn by combining the data compiled by the WOS statistical function. The influence of the publication is reflected by the $\mathrm{h}$-index value (a publication set has an h-index of $h$ if at least $h$ papers are cited at least $h$ times and all other papers in this set are cited fewer than $\mathrm{h}$ times), and the quality of the paper is reflected by the citation frequency (CPP). As shown in Figure 1 , the volume of publications (TP) generally shows an upward trend with changing year. The h-index value and the CPP trend of slowly rises and then decreases rapidly. The specifics can be divided into the following stages:

The first stage (developmental start-up period, 1990-1994): The annual number of publications is small, and the number is not very different, only $4-5$ articles. At this time, the reason for the small number of documents is mainly related to the fact that the research on infrared detection technology 
was in the initial stage, technical conditions and other factors, and the weak international academic exchange at that time. The h-index value and CPP showed a slowly rising trend, in which the h-index value had a relatively stable upward trend, and the CPP had a relatively large upward trend.

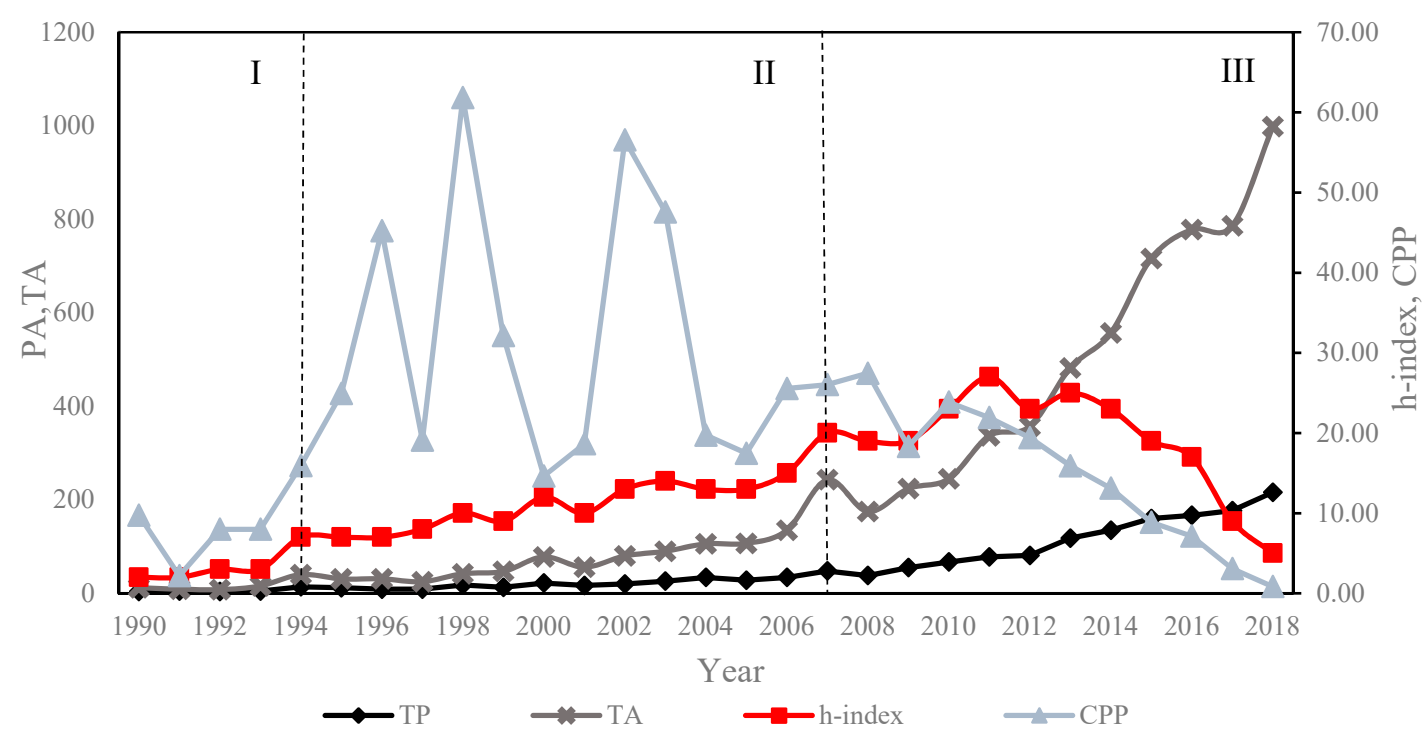

Figure 1. The line chart of the changes in annual TP, TA, h-index and CPP. TP, Total Publications; TA, Total Authors; CPP, Citations Per Paper.

The second stage (slowly fluctuating development period, 1994-2007): It can be seen in Figure 1 that the volume of volatility increases at this stage, but overall it is a slow growth trend, specifically from 14 in 1994 to 48 in 2007. The h-index value shows the same slow fluctuation trend as the published amount, whereas the CPP shows dramatic fluctuations. This stage indicates that infrared detection technology research is constantly being deepened, and new hotspots and technologies are constantly emerging.

The third stage (rapid development period, 2007-present): The number of publications in 2008 decreased slightly from 2007 to 38 . After 2008, the volume of publications grew rapidly every year. Although there were fluctuations, it was generally a rapid growth trend until the number of publications reached 216 in 2018. The h-index value and CPP population showed a rapid decline. The h-index value increased from the slow fluctuation in 2007 (20) to the rapid decline in 2013 (25). The reason may be related to the publication time of the literature. CPP is a cumulative statistic, so the early literature is cited more frequently, and the greater influence is a normal phenomenon.

At the same time, the total number of authors (TA) is also shown in Figure 1. It can be found that the variation curve of the total number of authors per year has a changing pattern similar to the variation of publication volume. In general, the research interest in infrared detection technology continues to increase, and researchers are constantly investing in it.

\subsection{Spatial Distribution of the Literature}

\subsubsection{Country/Regional distribution}

To fully grasp the national spatial distribution of infrared detection technology in the world, relevant data of the top 30 countries were counted, and the total number of publications reached 1727 . It can be seen in Figure 2 that there are 786 articles on the research of infrared detection technology in Europe, accounting for $45.51 \%$ of the total. In addition, its h-index value is also the highest, reaching 51. This shows that Europe is not only the most active area in the research of infrared detection technology, but its published literature is also the most influential. The Asian, American and Oceanic countries were ranked second, third and fourth, respectively. Although Oceania has the lowest number of publications, the CPP is the highest, reaching 20.83. Although the number of articles in the Asian 
region is ranked second, the CPP is the lowest, 8.95, and the h-index is ranked third, but it has reached 31. The reasons may be related to the large differences in the influence and quality of the literature published in Asia.

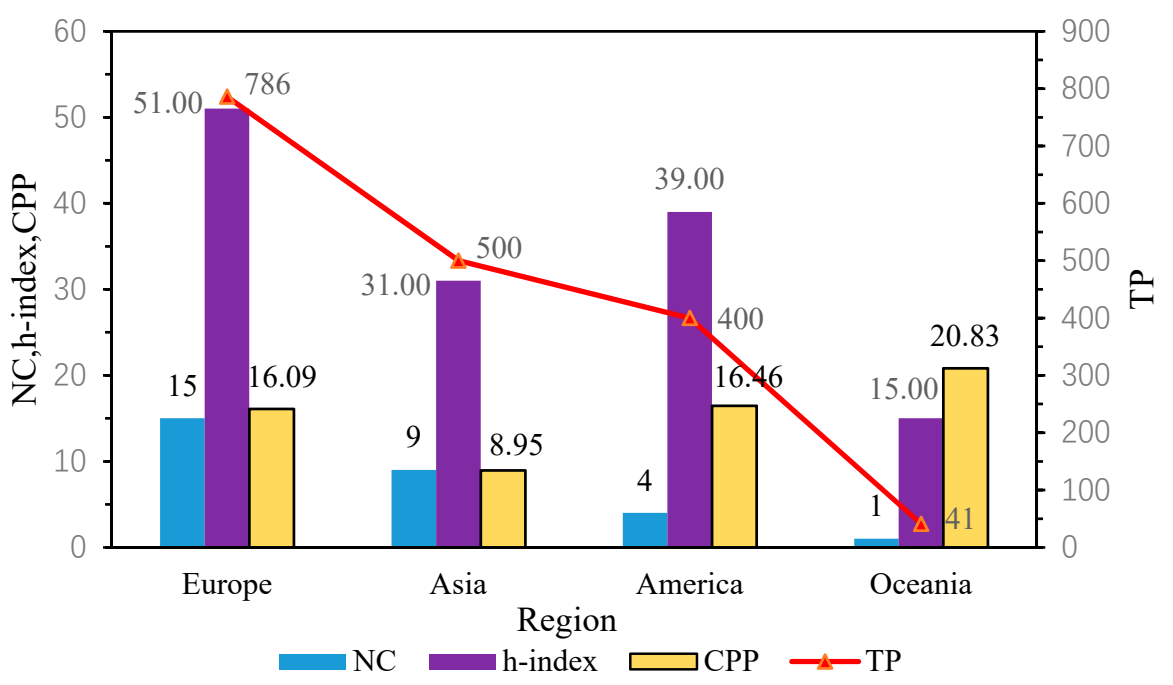

Figure 2. Regions that include the top 30 countries with the most publications. NC, Number of Countries; TP, Total Publications; CPP, Citations Per Paper.

To further explore the spatial distribution of the literature, the VOSviewer software was used to map the cohesive network density maps between different countries, as shown in Figure 3. The research interest on infrared detection technology in various countries is reflected by the network density map. Different countries are represented by different nodes, and the deeper is the color, the more documents are published in the country, which means that the country is highly active in the research on infrared detection technology. As shown in Figure 3, the Chinese node has the deepest color and the highest density, indicating that China is the most active country, followed by USA and Italy. In addition, it can be seen that many European countries have also played an important role, such as France, Germany, Great Britain, and Spain.

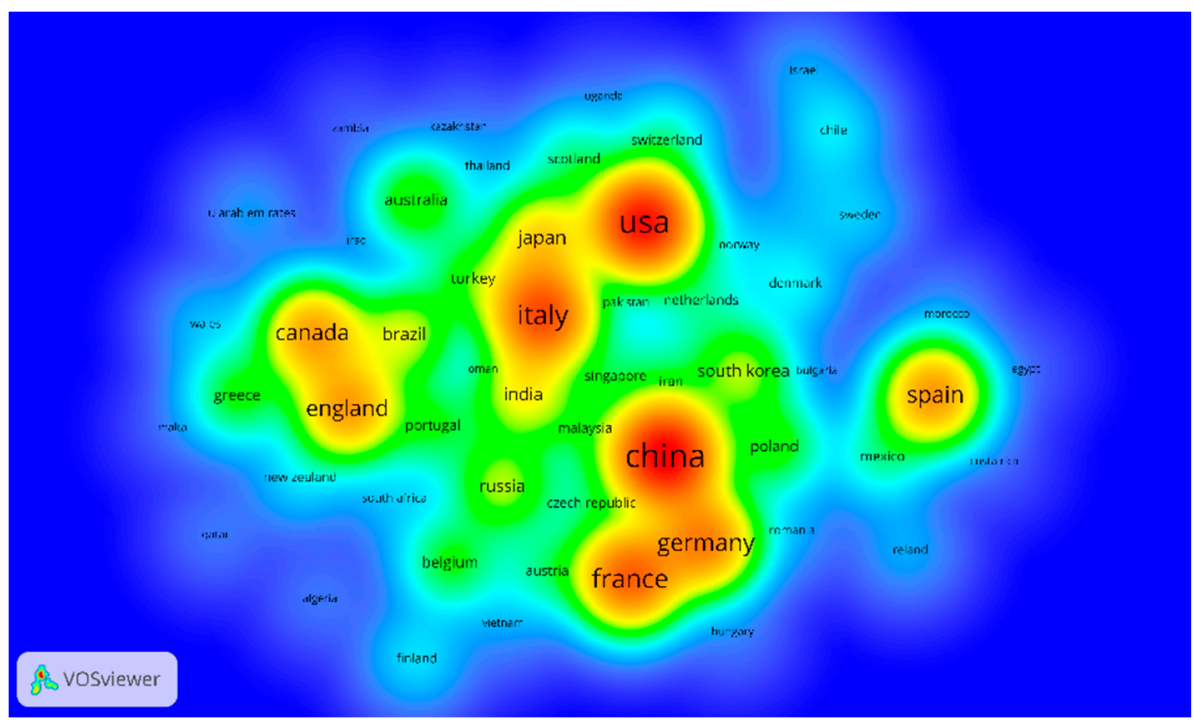

Figure 3. Country coauthoring network density knowledge map. 


\subsubsection{Organization Distribution}

From the perspective of the distribution of research organizations, the top ten research organizations, as well as their countries, h-index values and total citations are listed in Table 2. The Centre National de la Recherche Scientifique is the highest-volume research organization with 63 articles. Its h-index value and total citation frequency are ranked first, 18 and 1360 times, respectively. Laval University of Canada ranked second with 43 articles. This was followed by Tomsk Polytechnic University in Russia and the University of Naples Federico II in Naples, both with 29 articles, but the University of Naples Federico II h-index values and total citations are ranked in third and second, respectively, indicating that its published literature has higher influence and quality than that of Tomsk Polytechnic University. In addition, the University of California System in the USA, although its number of publications is not high, its h-index value of 17 is ranked second, and the articles are ranked highest by 37.19 times, indicating that the literature published by the research organization is very influential and plays an important role in infrared detection technology research.

Table 2. Distribution of the top 10 research organizations.

\begin{tabular}{cccccccc}
\hline Rank & Organization & Country & TP & $\mathbf{P}$ & h-Index & TC & CPP \\
\hline 1 & Centre National de la Recherche Scientifique & French & 63 & 3.903 & 18 & 1360 & 21.59 \\
\hline 2 & Laval University & Canada & 43 & 2.664 & 15 & 595 & 13.84 \\
\hline 3 & Tomsk Polytechnic University & Russia & 29 & 1.797 & 9 & 281 & 9.69 \\
\hline 4 & University of Naples Federico II & Italy & 29 & 1.797 & 16 & 732 & 25.24 \\
\hline 5 & CEA & French & 28 & 1.735 & 8 & 418 & 14.93 \\
\hline 6 & Consiglio Nazionale delle Ricerche & Italy & 27 & 1.673 & 9 & 334 & 12.37 \\
\hline 7 & University of California System & USA & 27 & 1.673 & 17 & 1004 & 37.19 \\
\hline 8 & Chinese Academy of Sciences & China & 24 & 1.487 & 7 & 183 & 7.63 \\
\hline 9 & University of Aquila & Italy & 24 & 1.487 & 11 & 250 & 10.42 \\
\hline 10 & Indian Institute of Technology System & India & 21 & 1.301 & 7 & 115 & 5.48 \\
\hline
\end{tabular}

TP, Total Publications; P, Proportion, \%; h, h-index; TC, Total Citations; CPP, Citations Per Paper.

The cooperation between various research organizations was considered, and VOSviewer software drew the coauthored network knowledge map between research organizations, as shown in Figure 4 . The cooperation relationship between different research organizations is the most important reflection of the network knowledge map. The number of documents published by the corresponding research organization is represented by the size of the node. The relationship between the two studies is represented by the connection line between the nodes, and the closeness of the connection is represented by the thickness of the connection line. It can be seen in Figure 4 that the two most closely related research organizations are Laval University and the University of Aquila, followed by the University of Science and Technology of China and Newcastle University in the UK. In addition, information about the number of partnerships is also expressed in Figure 4, with the largest number of partnerships being Laval University, followed by the University of California System and The University of Arizona. 


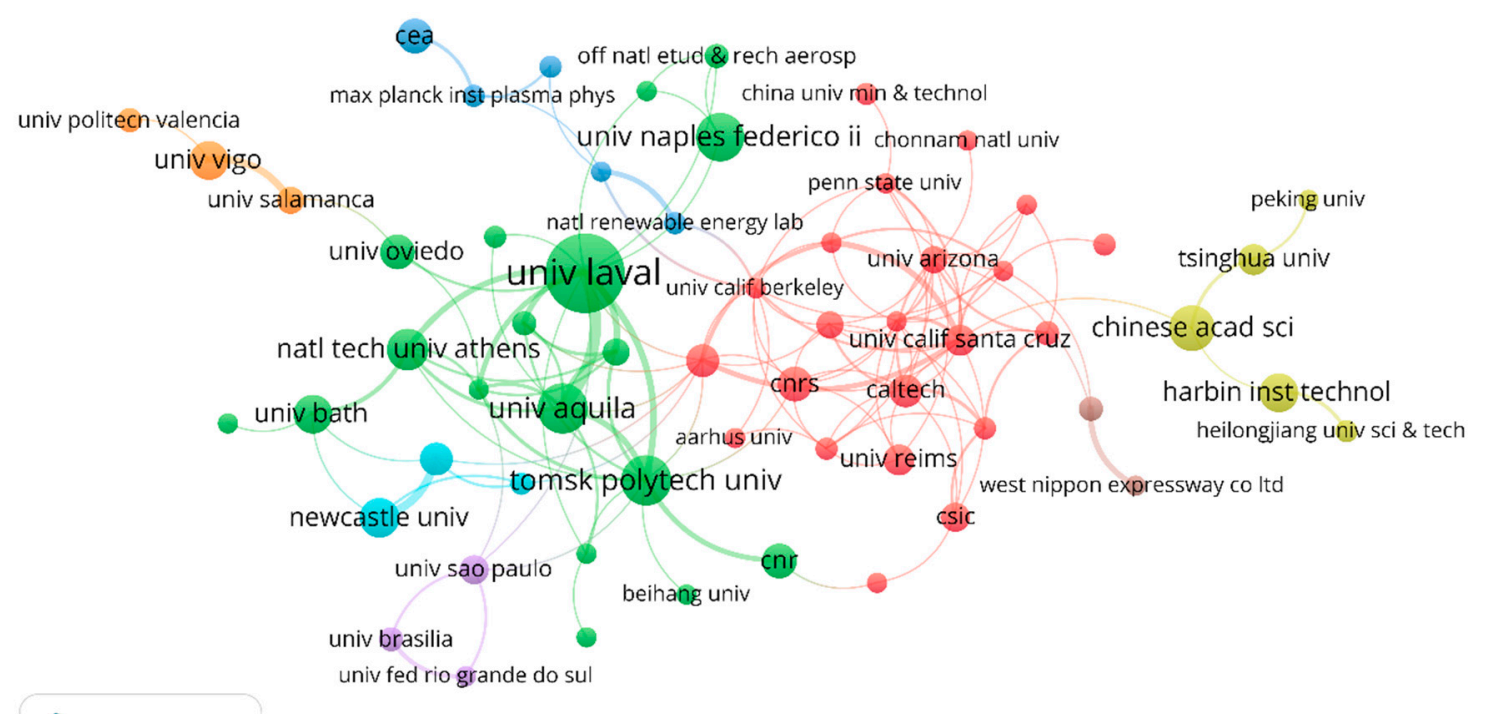

VOSviewer

Figure 4. Organizations coauthoring knowledge map.

\subsubsection{Publication Distribution}

Publications are the main carrier of academic communication. Through the analysis of statistical data, the core publications of infrared detection technology and its application fields can be found. The top 10 research publications are listed in Table 3. The journal with the largest number of publications is "Infrared Physics Technology", reaching 121 articles, accounting for $7.497 \%$ of the total, and its h-index value is also first at 20. To a certain extent, this reflects the great influence of "Infrared Physics Technology" in the field of infrared detection technology, and it is used by most researchers for reference and publication followed by "Ndt \& E International" and "Sensors", at 68 and 35, respectively. In general, it can be seen from the distribution of publications that most of the research on infrared detection technology is carried out around engineering, physics, and instrumentation.

Table 3. Distribution of the top 10 publications.

\begin{tabular}{cccccccc}
\hline Rank & Journal Title & Country & TP & $\mathbf{P}$ & h-Index & TC & CPP \\
\hline 1 & Infrared Physics Technology & Netherlands & 121 & 7.497 & 20 & 1658 & 13.7 \\
\hline 2 & Ndt \& E International & England & 68 & 4.213 & 20 & 1321 & 19.43 \\
\hline 3 & Sensors & Switzerland & 35 & 2.169 & 9 & 455 & 13 \\
\hline 4 & Insight & England & 23 & 1.425 & 6 & 113 & 4.91 \\
\hline 5 & Journal of Nondestructive Evaluation & USA & 23 & 1.425 & 8 & 233 & 10.13 \\
\hline 6 & Measurement Science and Technology & England & 18 & 1.115 & 6 & 113 & 6.28 \\
\hline 7 & Construction and Building Materials & England & 17 & 1.053 & 10 & 371 & 21.82 \\
\hline 8 & Energy and Buildings & Switzerland & 17 & 1.053 & 11 & 628 & 36.94 \\
\hline 9 & International Journal of Heat and Mass Transfer & England & 17 & 1.053 & 7 & 207 & 12.18 \\
\hline 10 & International Journal of Thermophysics & USA & 17 & 1.053 & 6 & 106 & 6.24 \\
\hline
\end{tabular}

TP, Total Publications; P, Proportion, \%; TC, Total Citations; CPP, Citations Per Paper.

We considered the cocitation relationship between publications based on the list. The cocited knowledge map of the infrared detection technology research publication was drawn by VOSviewer software. Publications are cited as one or more documents that simultaneously reference documents from two or more journals. It can be seen in Figure 5 that the journals "Infrared Physics Technology", "Ndt \& E International", "Astrophysical Journal", etc. have larger nodes, indicating that the frequency of their citations is higher, and it is basically consistent with Table 4 . The thickest links are the journals 
"Astrophysical Journal", "Monthly Notices of The Royal Astronomical Society" and "Astronomy Astronomical", indicating that the "Astrophysical Journal" and the other two journals have been cited the most. This is followed by the journal "P Soc Photo-opt Ins" and the "Journal of Applied Physics". In addition, nodes of the same color are grouped together to represent a cluster, different clusters are represented by different colors, and the types of publications in the same cluster have high literacy, which means that they are frequently cited together, such as the "Journal of Dairy Science" in the green cluster and the journal "Computers and Electronics in Agriculture". In general, the journals of infrared detection technology that are mainly disseminated, and referenced, are "Infrared Physics Technology", "Ndt \& E International", "Astrophysical Journal", etc.

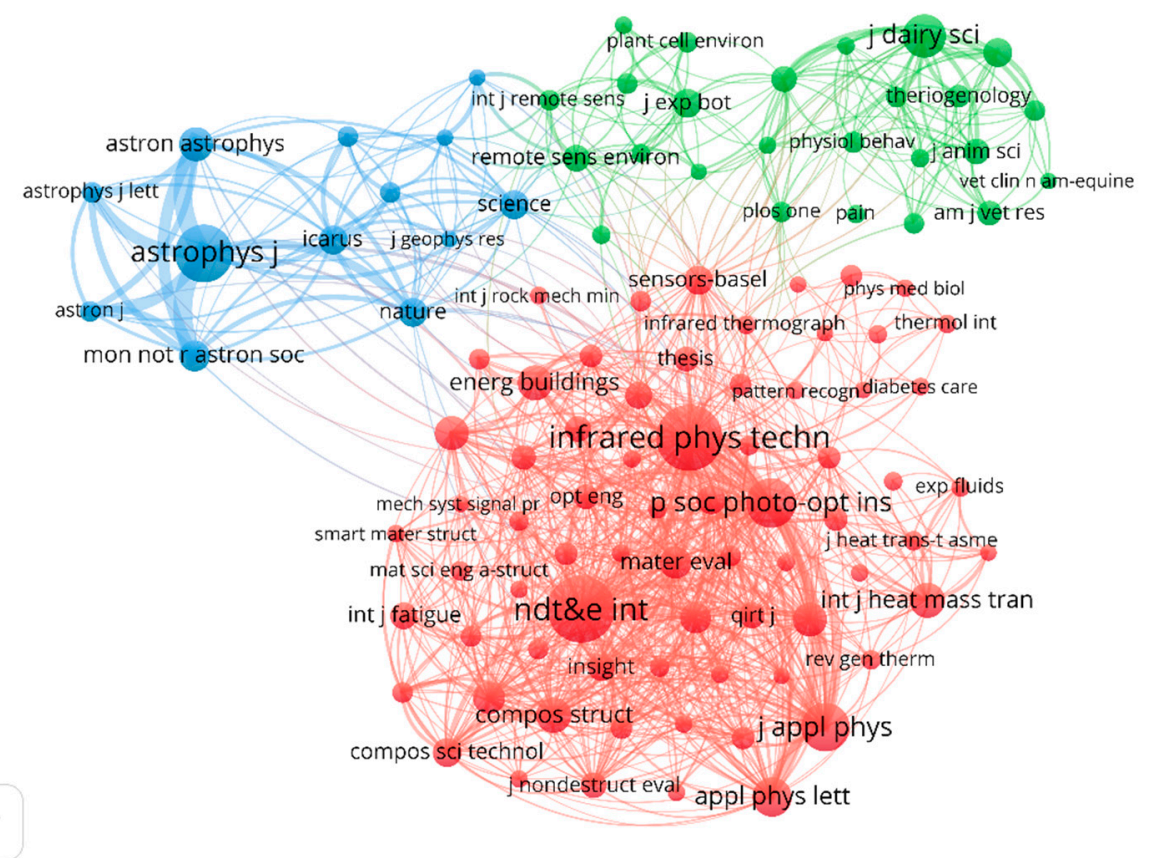

Figure 5. Publication cocitation knowledge map. 
Table 4. The top 30 research directions.

\begin{tabular}{|c|c|c|c|c|c|c|c|c|c|}
\hline Rank & Research Interest & $\mathbf{T P}$ & $\mathbf{h}$ & CPP & Rank & Research Interest & TP & $\mathbf{h}$ & CPP \\
\hline 1 & Engineering & 403 & 36 & 14.27 & 16 & Computer Science & 38 & 10 & 17.16 \\
\hline 2 & Materials Science & 386 & 34 & 13.03 & 17 & Radiology Nuclear Medicine Medical Imaging & 28 & 13 & 24.29 \\
\hline 3 & Instruments Instrumentation & 280 & 27 & 10.96 & 18 & Plant Sciences & 26 & 15 & 54.46 \\
\hline 4 & Physics & 280 & 27 & 11.06 & 19 & Food Science Technology & 25 & 10 & 20.84 \\
\hline 5 & Optics & 171 & 23 & 12.53 & 20 & Geology & 24 & 10 & 16.63 \\
\hline 6 & Chemistry & 113 & 20 & 11.91 & 21 & Nuclear Science Technology & 24 & 8 & 12.96 \\
\hline 7 & Mechanics & 90 & 16 & 13.51 & 22 & Polymer Science & 22 & 7 & 6.77 \\
\hline 8 & Veterinary Sciences & 89 & 20 & 12.25 & 23 & Environmental Sciences Ecology & 20 & 11 & 16.45 \\
\hline 9 & Thermodynamics & 85 & 16 & 9.78 & 24 & Imaging Science Photographic Technology & 20 & 7 & 24.25 \\
\hline 10 & Agriculture & 82 & 19 & 14.72 & 25 & Spectroscopy & 18 & 5 & 3.06 \\
\hline 11 & Construction Building Technology & 65 & 21 & 21.09 & 26 & Surgery & 18 & 8 & 15.56 \\
\hline 12 & Energy Fuels & 60 & 19 & 18.25 & 27 & Biochemistry Molecular Biology & 17 & 8 & 13.59 \\
\hline 13 & Science Technology Other Topics & 59 & 18 & 16.59 & 28 & Remote Sensing & 17 & 6 & 11.65 \\
\hline 14 & Electrochemistry & 50 & 12 & 11.84 & 29 & Automation Control Systems & 16 & 4 & 4.75 \\
\hline 15 & Astronomy Astrophysics & 41 & 20 & 31.76 & 30 & Geochemistry Geophysics & 16 & 9 & 17.75 \\
\hline
\end{tabular}




\subsubsection{Subject Categories Distribution}

Infrared detection technology is used in many fields, such as construction, military, industry, medicine and others. It can be seen in Table 4 that infrared detection technology has as many as 100 research directions, including engineering, materials science, equipment, physics, optics and so on. Among them, engineering has the highest document count and h-index, 403 and 36, respectively. The research direction with the CPP is "Plant Sciences" with a ranking of 18, reaching 54.46 times. In general, the research direction of infrared detection technology mainly focuses on two fields: detection and civil use.

\subsection{Research Focus Analysis}

\subsubsection{Literature Cocitation Analysis}

By analyzing the highly cited literature, we explored the core content of infrared detection technology research. The top 10 literature citations were counted and relevant data such as publications, authors, publication year, number of co-organizers, and number of colocated countries are listed in Table 5.

In Table 5, that seven of the ten articles are essay-type documents and three are literature reviews. The highest cited frequency was Rogalski's "Infrared detectors: status and trends", published in "Progress in Quantum Electronics" in 2003, which was cited 585 times. The status and trends of infrared detectors are reviewed in this article, and it describes the infrared detector research direction to improve the performance of unipolar devices, large electronic scanning arrays and higher operating temperatures. The performance of different infrared detectors and the application principles are studied, and the development of uncooled thermal imaging technology is introduced [30]. Ranked second in the cited frequency is "The dynamic compressive behavior of beryllium bearing bulk metallic glasses" by HA Bruck et al., published in the "Journal of Materials Research" in 1996. It was the first study of metallic glass dynamically compressing yield behavior and using a high-speed infrared heat detector to determine whether adiabatic heating occurs during the dynamic deformation of the metallic glass [31]. Ranked third is "A reappraisal of the use of infrared thermal image analysis in medicine" written by BF Jones in 1998. This document is published in the publication "IEEE Transactions on Medical Imaging", which describes the application and development of infrared detection technology in the medical field. It expounds on the physical principles of thermal imaging, analyzes the infrared thermal image of human skin and introduces the infrared camera to medical development [32]. In fourth place is "High-throughput screening of solid-state catalyst libraries" by SM Senkan. This article describes the use of high-speed screening in the field of materials using infrared cameras [33]. Ranked fifth is J Philip's review of the basics of the thermal imaging camera, basic theoretical background, various measurements and its application in various medical fields in "Medical applications of infrared thermography: A review" [34]. In general, these 10 highly cited documents are well-recognized and referenced by researchers who are interested in infrared detection technology. 
Table 5. Top 10 papers with the most citations.

\begin{tabular}{|c|c|c|c|c|c|c|c|c|}
\hline Rank & Title & Type & Journal & Authors & Year & Citations & IN & CN \\
\hline 1 & Infrared detectors: status and trends & Review & $\begin{array}{l}\text { Progress in } \\
\text { Quantum Electronics }\end{array}$ & A Rogalski & 2003 & 585 & 1 & 1 \\
\hline 2 & $\begin{array}{l}\text { The dynamic compressive behavior of beryllium bearing } \\
\text { bulk metallic glasses }\end{array}$ & Article & $\begin{array}{l}\text { Journal of } \\
\text { Materials Research }\end{array}$ & HA Bruck, et al. & 1996 & 280 & 2 & 1 \\
\hline 3 & $\begin{array}{l}\text { A reappraisal of the use of infrared thermal image analysis } \\
\text { in medicine }\end{array}$ & Article & $\begin{array}{l}\text { IEEE Transactions on } \\
\text { Medical Imaging }\end{array}$ & BF Jones & 1998 & 257 & 1 & 1 \\
\hline 4 & High-throughput screening of solid-state catalyst libraries & Article & Nature & SM Senkan & 1998 & 255 & 1 & 1 \\
\hline 5 & Medical applications of infrared thermography: A review & Review & $\begin{array}{l}\text { Infrared Physics \& } \\
\text { Technology }\end{array}$ & J Philip & 2012 & 242 & 1 & 1 \\
\hline 6 & Infrared thermography for condition monitoring-A review & Review & $\begin{array}{l}\text { Infrared Physics \& } \\
\text { Technology }\end{array}$ & BB Lahiri, et al. & 2013 & 227 & 1 & 1 \\
\hline 7 & $\begin{array}{l}\text { Use of infrared thermography for monitoring stomatal } \\
\text { closure in the field: application to grapevine }\end{array}$ & Article & $\begin{array}{l}\text { Journal of } \\
\text { Experimental Botany }\end{array}$ & HG Jones, et al. & 2002 & 220 & 3 & 2 \\
\hline 8 & $\begin{array}{l}\text { Fatigue limit evaluation of metals using an infrared } \\
\text { thermographic technique }\end{array}$ & Article & Mechanics of Materials & MP Luong & 1998 & 213 & 3 & 1 \\
\hline 9 & $\begin{array}{l}\text { Use of infrared thermal imaging to isolate Arabidopsis } \\
\text { mutants defective in stomatal regulation }\end{array}$ & Article & Plant Journal & S Merlot, et al. & 2002 & 198 & 4 & 1 \\
\hline 10 & Infrared thermography for building diagnostics & Article & Energy and Buildings & CA Balaras, et al. & 2002 & 198 & 1 & 1 \\
\hline
\end{tabular}

IN, Institute Number; CP, Country Number. 


\subsubsection{Author Cocitation Analysis}

Since infrared detection technology has been widely promoted, researchers in different fields are constantly conducting in-depth research. From the data in the WOS core database, as many as 5476 researchers worked on infrared detection technology. The authors of the top 10 posts (the total number of people enumerated is 14 because some have the same number of documents) are listed in Table 6, and the first two authors are from the same institution in Canada, Laval University, X Maldague and $\mathrm{C}$ Ibarra-Castanedo. At the same time, the h-index values of $\mathrm{X}$ Maldague and $\mathrm{C}$ Ibarra-Castanedo are also the highest, reaching 14. In second, Italy's GM Carlomagno reaches 11. Then, S Sfarra and $\mathrm{C}$ Meola from Italy reaches 10 . The author with the highest number of citations is AL Schaefer from the University of Alberta, who has been cited 527 times. X Maldague and GM Carlomagno ranked second and third, respectively, with 502 and 486.

Table 6. Top 10 authors with the most publications.

\begin{tabular}{cccccccc}
\hline Rank & Author & Country & Institute & TP & P & h & TC \\
\hline 1 & X Maldague & Canada & Laval University & 31 & 1.921 & 14 & 502 \\
\hline 2 & C Ibarra-Castanedo & Canada & Laval University & 29 & 1.797 & 14 & 467 \\
\hline 3 & S Sfarra & Italy & University of Aquila & 22 & 1.363 & 10 & 233 \\
\hline 4 & GM Carlomagno & Italy & Univ Naples Federico II & 16 & 0.991 & 11 & 486 \\
\hline 4 & H Zhang & Canada & Laval University & 16 & 0.991 & 7 & 206 \\
\hline 6 & NP Avdelidis & Greece & Natl Tech Univ Athens & 15 & 0.929 & 9 & 284 \\
\hline 6 & C Meola & Italy & Univ Naples Federico II & 15 & 0.929 & 10 & 404 \\
\hline 6 & Y Wang & China & Harbin Institute of Technology & 15 & 0.929 & 7 & 108 \\
\hline 9 & R Mulaveesala & Indian & Indian Inst Technol Ropar & 14 & 0.867 & 8 & 202 \\
\hline 10 & JL Bodnar & French & UNIVERSITE DE REIMS & 13 & 0.805 & 5 & 73 \\
\hline 10 & S Laguela & Spain & Universidad De Salamanca & 13 & 0.805 & 7 & 185 \\
\hline 10 & JY Liu & China & Harbin Institute of Technology & 13 & 0.805 & 6 & 87 \\
\hline 10 & AL Schaefer & Canada & University of Alberta & 13 & 0.805 & 8 & 527 \\
\hline 10 & VP Vavilov & Russia & Tomsk Polytech University & 13 & 0.805 & 6 & 116 \\
\hline
\end{tabular}

TP, Total Publications; P, Proportion, \%; h, h-index; TC, Total Citations.

To show the high thermal degree of the infrared detection technology research, VOSviewer software was used to map the author's cocited knowledge map, as shown in Figure 6. It can be seen from the node size that X Maldague has the highest citation frequency, followed by $\mathrm{C}$ Meola and $\mathrm{C}$ Ibarra-Castanedo. It is seen that the number of joints between X Maldague and C Meola is the highest among the number of node connections, followed by NP Avdelidis and E Grinzato. It can also be found that C Meola and C Ibarra-Castanedo are also the most commonly cited, followed by E Ng and M Etehadtavakol. Five clusters are displayed by the author's cocited knowledge map. Among them, red, green and yellow clusters are closely linked and intersect each other. This indicates that the authors of these three types of clusters have close contact in the research of infrared detection technology, and can be applied together in a certain field. However, purple clustering has nothing to do with the other four categories. We can explore whether the relationship between the purple cluster authors and other clusters can establish a relationship that can also provide a new trend for infrared detection technology research. 


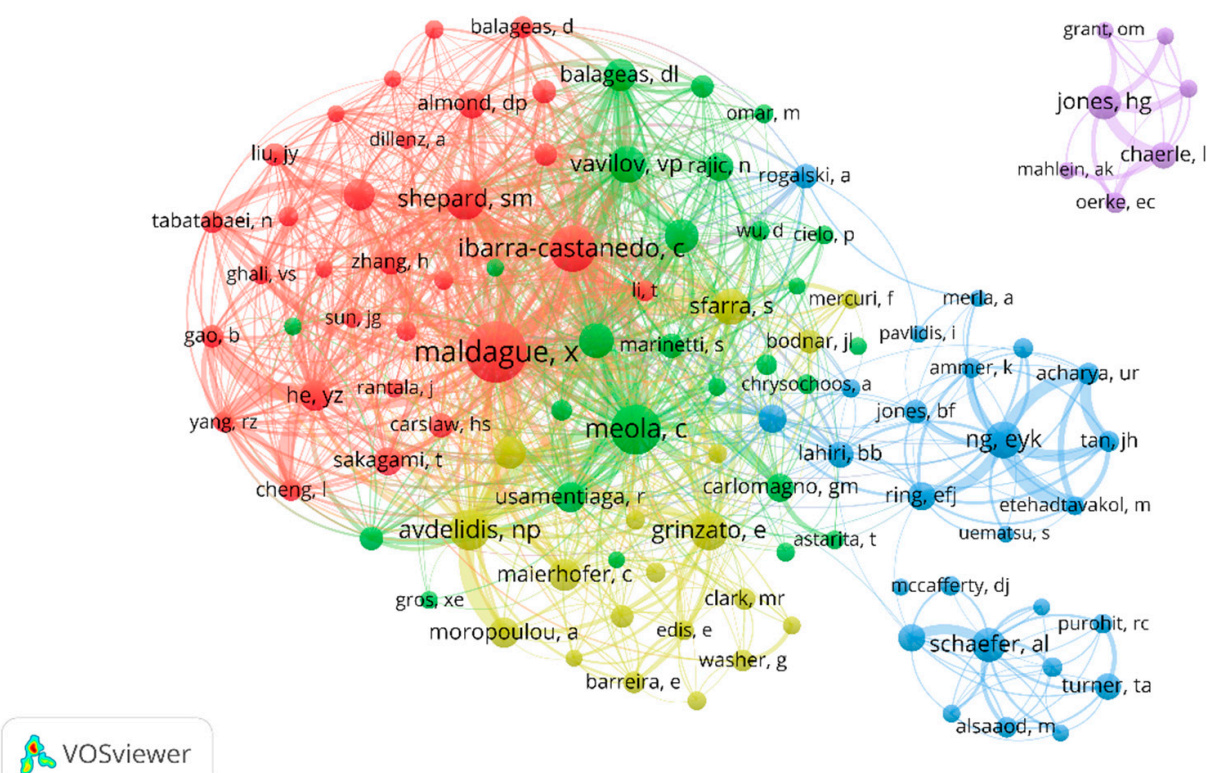

Figure 6. Author cocitation network.

\subsection{Keyword Co-Occurrence Analysis}

\subsubsection{Keyword Co-Occurrence Network}

Keywords provide information about the core content of an article, thus keyword analysis can be used to identify evolving research fronts related to the knowledge domain [35]. We used VOSviewer software to draw the keyword co-occurrence knowledge map of the research literature on infrared detection technology, as shown in Figure 7. In the keyword co-occurrence knowledge map, the nodes of the same color represent a cluster, and the keywords in the same cluster are closely related, and the links between different clusters explore the relationships contained therein. As shown in figure, these keywords are divided into five clusters, represented by green, red, blue, yellow, and purple.

B vosviewer

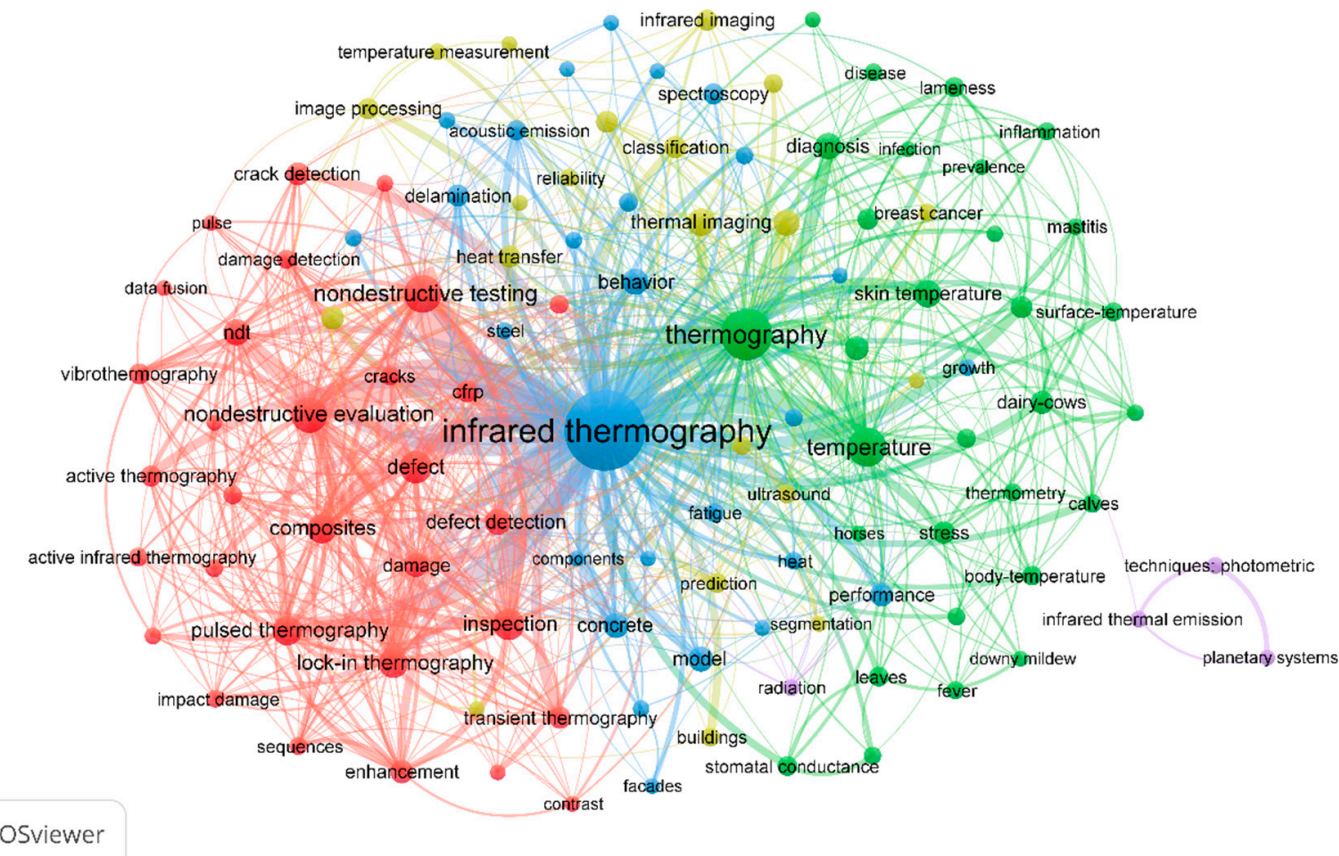

Figure 7. Keyword cocitation knowledge map of infrared detection technology studies. 
Cluster 1 (green): Green clustering is mainly applied to the research of infrared detection technology in the fields of medicine, veterinary science, animal husbandry and agriculture. Among them, the keyword with the most frequency and connected nodes is "thermography", followed by "temperature" and "thermal imaging", among which temperature is the most important indicator of the life sciences field. The medical applications can be found by the keyword "body-temperature". For example, AF De Salis et al. [36] investigated whether changes in blood flow in vertebral fractures cause changes in skin temperature that can be passed. High-resolution thermal imaging (HRTI) aids in the diagnosis and monitoring of fractures in patients with osteogenesis imperfecta. F Mohammadi et al. [37] evaluated the depth and radius of a tumor by analyzing the infrared thermography. Through the keywords "leaves" and "dairy-cows", it can be found that, in animal husbandry and agriculture, M Sathiyabarathi et al. [38] used infrared cameras to screen and detect early mastitis in hybrid cows. A Pou et al. [39] applied thermal imaging technology to detect the water condition of plants, with the main purpose of monitoring the field of drought threat.

Cluster 2 (red): The red cluster is mainly used for nondestructive testing with infrared detection technology, and it is mainly used in materials, construction, electric power, machinery and other fields. It can also be seen from the keywords "nondestructive evaluation", "nondestructive testing", and "defect detection", which have a high frequency of occurrence. It can be seen that infrared detection technology is active in nondestructive testing. For example, the keyword "composites" can be used to determine the fatigue limit of composites quickly and reliably with EZ Kordatos et al. [40] using a combination of infrared trichoelectric thermography and acoustic emission. This also shows us the new direction of infrared detection technology in nondestructive testing, and explores more convenient and efficient detection methods by combining with other detection technologies. At the same time, this cluster also shows us four methods of infrared detection technology: pulsed thermography proposed by Milne and Reynolds [41]; lock-in thermography by G Busse of Stuttgart University, Germany [42]; pulsed phase thermography proposed by Maldague of Laval University, Canada [43]; and ultrasonic thermography by Favro et al. [44].

Cluster 3 (blue): The keyword "infrared thermography" in the blue cluster is the node with the highest frequency, the most connected lines and the strongest connection strength. One of the reasons is that "infrared thermography" is related to the search term, and another is that the keyword is the theoretical core. Although infrared cameras are the main detection tools, the development of infrared cameras can also be indirect. It shows that the development of infrared detection technology has been studied throughout the period. The clustering keyword mainly shows the principle, development process, performance, application field and model structure of the infrared camera. The keyword "concrete" can be used to understand that the infrared camera is used in the construction field, especially for the detection of concrete. For example, TM Cheng et al. [45] studied how to actively combine infrared cameras with elastic wave technology to evaluate the state of concrete structures with few resources.

Cluster 4 (yellow): The yellow clusters are scattered, but they are closely related to other clusters. The biggest keywords for nodes are "thermal imaging" and "system". This mainly reflects the research of image processing technology after thermal imaging and the exploration of thermal imaging systems. For example, Lahiri et al. [34] studied the progress of infrared cameras in the medical field, and analyzed the basic theoretical background, measurement methods, image processing, data analysis and numerical simulation of infrared cameras.

Cluster 5 (purple): Purple is a small cluster with only four keywords: "infrared thermal emission", "planetary systems", "radiation", and "photometric techniques". From the keywords, space is the main research object. For example, L Kreidberg et al. [46] searched for atmospheric properties by accurate near-infrared transmission spectra of Jupiter's WASP-12b to find strong evidence of water uptake.

In general, the research hotspots for infrared detection technology in the past 30 years have been fully demonstrated by the keyword co-occurrence network knowledge map, and the connection of various research directions. The infrared thermal imaging camera is the main embodiment of infrared 
detection technology. It determines the temperature distribution of an object or region of interest in a short time with statistical analysis of anomalies.

\subsubsection{Keyword Timeline View}

The keyword co-occurrence knowledge map does not show the time distribution of hotspots well, for studying the development and trend of infrared detection technology. Therefore, Citespace software was used to draw the keyword timeline view, as shown in Figure 8.

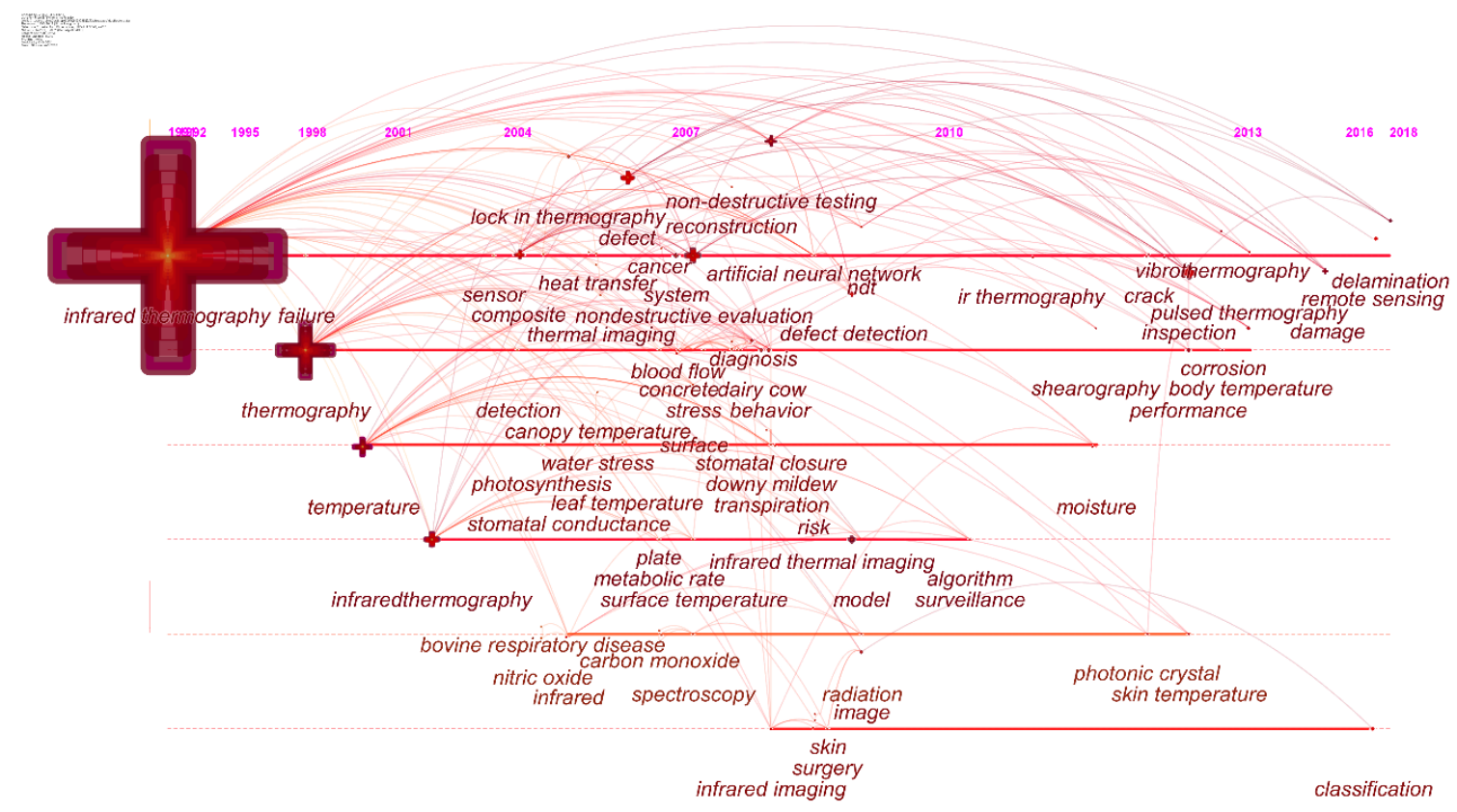

Figure 8. Keyword timeline view of infrared detection technology studies.

The infrared detection technology hotspot change with time is described by the keyword timeline view, with time as the x-axis and keyword as the y-axis. The horizontal analysis is of the earliest keyword period and its research progress, and a longitudinal analysis is of the differences and linkages of different clustering keywords. The keywords all correspond to the nodes in the graph. The larger is the node, the more frequently do the corresponding keywords appear in a year. The sudden strength of the keyword is represented by the node color depth, which also means that the keyword is a hot spot in that period.

Figure 8 shows that the nodes with higher frequency appearing in the keyword timeline view are "infrared thermography", "thermography", and "temperature", and these three keywords are also the first words appearing in the cluster. It means that this is a new research hotspot and direction at that time. The data retrieval time was from 1990 to 2018. It can be seen from the figure that "infrared thermography" has been a hot spot since 1990. It also runs through the whole period of research and is basically related to each keyword. It means that, with the continuous development, infrared detection technology will be more and more widely used in various fields. At the same time, through the "infrared thermography" timeline view, it can be found that the words "lock-in thermography", "defect", "nondestructive evaluation" and "nondestructive testing" appear between 2004 and 2008. In this period, the application of infrared detection technology to nondestructive testing was a hot spot and was rapidly developed.

In the past five years, sudden hot spots have increased. Vibration thermal imaging, pulse thermal imaging, photonic crystals, skin temperature and remote sensing technology has become the hotspots for infrared detection technology, and the key to sudden emergence in 2018 the word "delamination" indicates that the latest research hotspot is the detection of delamination defects with infrared cameras, mainly for the detection of layered structures or material and concrete delamination in the construction 
field. For example, Montinaro et al. [47] detected the debonding defects between aerospace grade fiber metal laminate layers by analyzing the characteristics of the thermal image obtained by the nondestructive infrared testing device. QH Tran et al. [48] used a square pulse thermal imager to analyze various heating and environmental conditions for concrete samples, aiming to comprehensively study the effect of steel on stratification detection capability when the width to depth ratio of the layer is equal to or less than 2.0.

There are six timelines in Figure 8 that are the progress time distributions of the six clusters. In addition to the infrared camera, the timeline view of applying this clustering to nondestructive testing is also studied by thermal imaging methods, temperature distribution analysis, image processing technology research, and applications in various fields. Among them, an emerging research hotspot in the past 10 years is making image processing technology more intuitive, accurate and easy for detection and analysis.

As shown in Table 7, Citespace software is obtained by the PathFinder algorithm, in which the 22 keywords with the strongest burst strength are listed, as well as start time, end time and intensity. Table 7 shows that the research hot spots are constantly changing each year, and the break out time for keywords is also different. The key to the most explosive outbreak is inspection, which broke out between 2016 and 2018. It is known that inspection is a hot topic in recent years, involving many fields, such as construction, electric power, industrial fields, etc. At the same time, pulsed thermography, nondestructive evaluation, etc. are also keywords with high breakout strength. It can be found that inspections, evaluations, and principles and applications are involved in nondestructive testing. The hotspots that erupt in different time periods are also different, such as the principle and application breakout during 2016-2018, and the detection breakout during 2013-2015. We also found that the keywords with strong bursts in the table are basically highlighted in the past ten years, which also indicates that the interest in infrared detection technology has been increasing in the past decade, and the research content is getting more and more abundant.

Table 7. Top 20 keywords with the most burst strength.

\begin{tabular}{|c|c|c|c|c|c|}
\hline Rank & Keywords & Strength & Begin & End & 1990-2018 \\
\hline 1 & inspection & 14.0359 & 2016 & 2018 & - \\
\hline 2 & $\begin{array}{c}\text { pulsed } \\
\text { thermography }\end{array}$ & 7.1643 & 2013 & 2015 & \\
\hline 3 & $\begin{array}{c}\text { nondestructive } \\
\text { evaluation }\end{array}$ & 7.1484 & 2016 & 2018 & 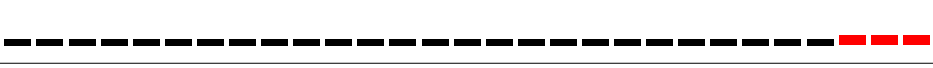 \\
\hline 4 & stress & 6.6315 & 2011 & 2013 & \\
\hline 5 & $\begin{array}{l}\text { nondestructive } \\
\text { testing }\end{array}$ & 6.4173 & 2013 & 2015 & - \\
\hline 6 & $\begin{array}{c}\text { body } \\
\text { temperature }\end{array}$ & 6.0271 & 2013 & 2014 & \\
\hline 7 & $\begin{array}{c}\text { infrared } \\
\text { thermography }\end{array}$ & 5.9422 & 1999 & 2000 & \\
\hline 8 & composite & 5.3071 & 2015 & 2018 & سمس \\
\hline 9 & $\begin{array}{l}\text { infrared } \\
\text { imaging }\end{array}$ & 4.6667 & 2008 & 2011 & 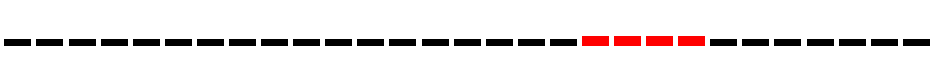 \\
\hline 10 & infrared & 4.4979 & 2005 & 2012 & 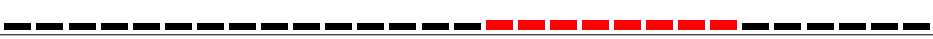 \\
\hline 11 & thermography & 4.1896 & 2002 & 2003 & \\
\hline 12 & classification & 4.0919 & 2017 & 2018 & \\
\hline 13 & $\begin{array}{l}\text { remote } \\
\text { sensing }\end{array}$ & 4.0919 & 2017 & 2018 & \\
\hline 14 & $\begin{array}{c}\text { lock-in } \\
\text { thermography }\end{array}$ & 4.014 & 2016 & 2016 & \\
\hline 15 & $\begin{array}{c}\text { infrared } \\
\text { thermography }\end{array}$ & 3.8382 & 2016 & 2018 & שים \\
\hline 16 & performance & 3.8301 & 2016 & 2016 & - \\
\hline 17 & blood flow & 3.7882 & 2007 & 2013 & \\
\hline 18 & damage & 3.7776 & 2015 & 2015 & 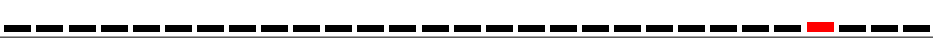 \\
\hline 19 & defect & 3.7195 & 2014 & 2018 & 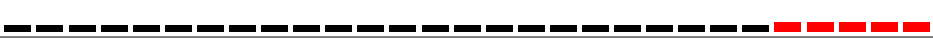 \\
\hline 20 & diagnosis & 3.6729 & 2015 & 2015 & - \\
\hline
\end{tabular}




\subsection{Research Evolution Analysis}

Infrared detection is a newly developed nondestructive testing technology. The main evolution presents the process from knowledge theory to practical application. The main three aspects are the basic theory of infrared detection technology, infrared thermal imaging and new infrared detection technology. The specific evolutionary path is shown in Figure 9.

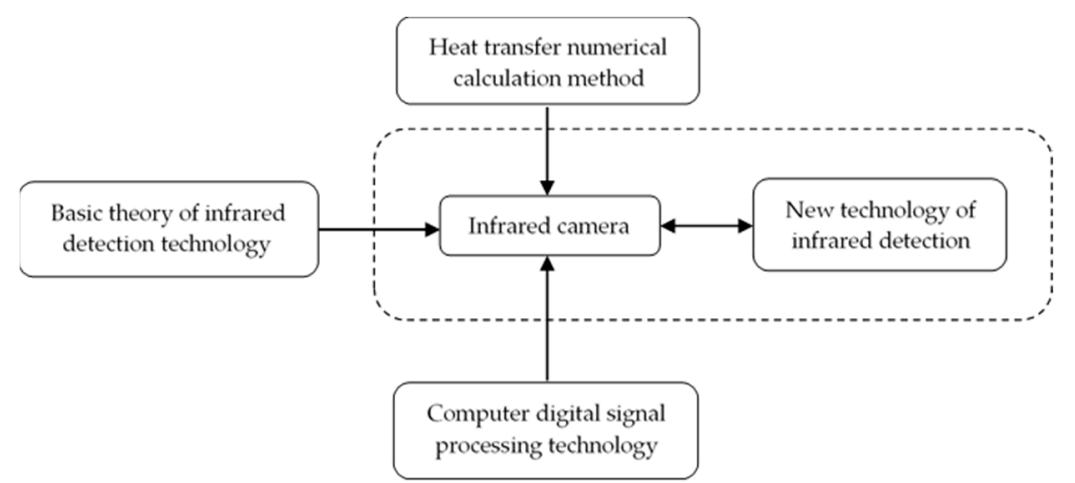

Figure 9. Evolutionary path of infrared detection technology studies.

The basic theory of infrared detection technology was first proposed in the 1960s by Green and Alzofon, mainly to study the possibility of infrared detection but it is still in its infancy. In the 1970s, with the work done by Carlslaw [49] as a representative, the heat conduction theory was gradually introduced into the research of infrared thermal image detection. Subsequent research has been mainly about heat transfer around heterogeneous bodies. The typical representative is Maldague [50] and others. They successively modeled one- and two-dimensional heat conduction under different thermal or cold excitation conditions and obtained corresponding analytic or numerical solutions. The theoretical basis of infrared detection technology is provided by these works.

From the late 1980s up to now, the development of infrared detection technology based on infrared cameras continuously improved the acquisition rate, image number, sensitivity and other aspects, developed computer digital signal processing technology and explored heat transfer numerical calculation methods. New detection methods and signal processing techniques have been continuously proposed to improve the accuracy of infrared thermal image detection. Representative of the comparison is pulsed, lock-in, pulse phase and ultrasonic thermography. At the same time, with the hot spot of infrared detection technology continuously improving, various new technologies for infrared thermal image detection and evaluation have emerged.

The evolution of infrared detection technology is shown in Figure 10. There are seven clusters, marked in order of appearance to helps us better understand the development context. It can be found that most evolution of infrared detection technology began with exploring the theory and methods for infrared thermal imaging. Then, gradually good applications and results were achieved in the three directions of life science, nondestructive testing and condition monitoring. Among them, medical diagnoses, animal and plant vital signs are mainly diagnosed in the life science direction; nondestructive testing is mainly for research on new methods and technologies for construction, machinery and electrical; and the state monitoring direction mainly reflects real-time monitoring of state, deformation, abnormality and quality assurance for industrial machinery and electrical equipment. At the same time, the technical level development represented by pattern recognition and computer-aided detection or diagnosis is also an important branch in the evolution process, providing technical support for infrared detection technology, optimizing the thermal imaging map, and improving its adaptability. 


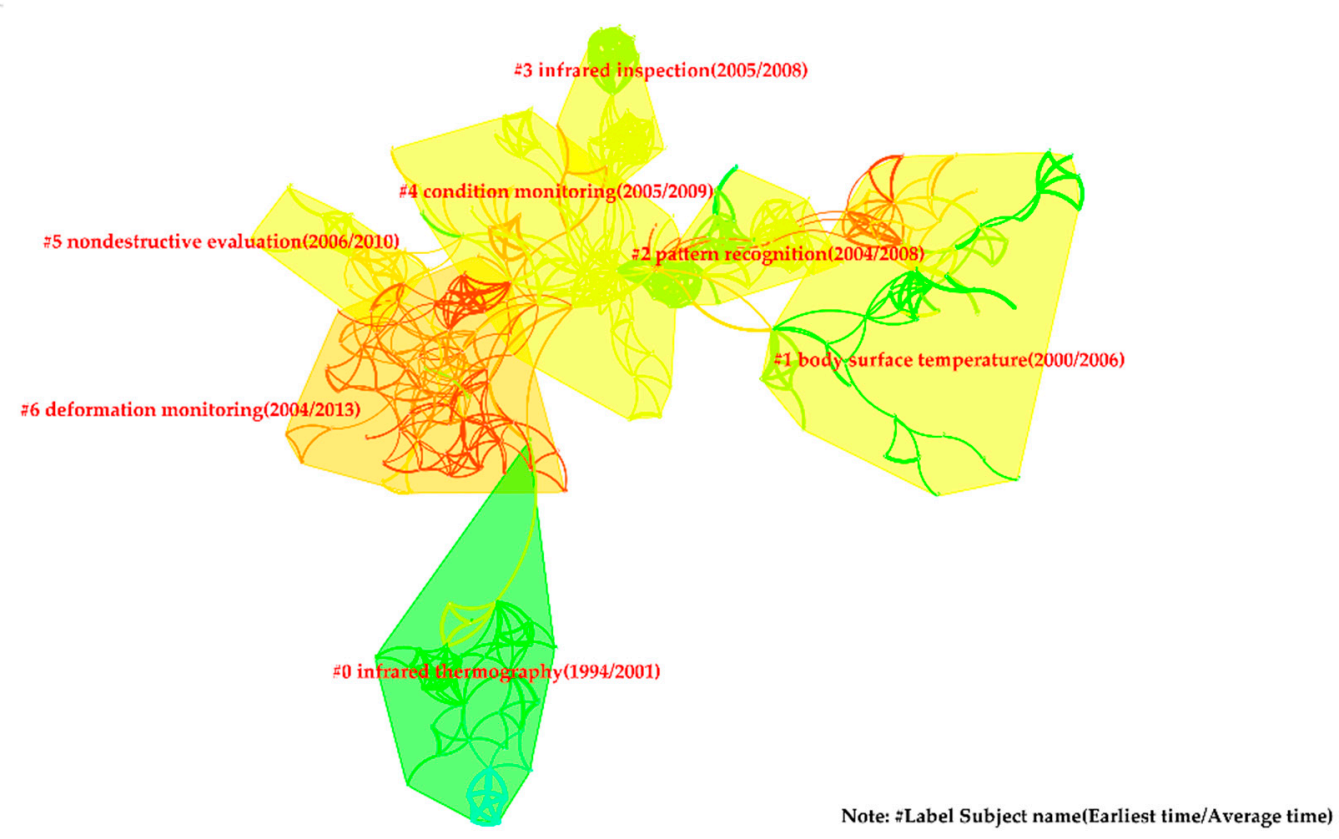

Figure 10. Keyword evolution co-occurrence knowledge map of infrared detection technology studies.

In addition, we also found that the main research direction for future development of infrared detection technology is to overcome technical difficulties. The new infrared detection technology corresponds to a more advanced infrared camera. Therefore, in addition to medical infrared cameras, it is necessary to develop special infrared products suitable for as many other fields as possible to enhance the applicability of infrared detection technology. In the fields of military, medicine, construction, electric power, etc., many applications of infrared detection technology have been obtained, showing that it will play an increasingly important role in human life.

\section{Conclusions}

We used the bibliometric method and visualization technology to analyze the spatiotemporal distribution, research hotspots and trends for infrared detection technology research literature, and used VOSviewer and Citespace software to draw relevant scientific knowledge graphs and the following conclusions:

(1) The total number of articles and authors is on the rise, indicating that research on infrared detection technology is rapidly developing in the global academic community. Countries such as China, the USA, and Italy are development centers and active areas for infrared detection technology. French research organizations such as the Centre National de la Recherche Scientifique are more prominent in the research of infrared detection technology, and they have a large number of publications and a high average article quality. The journals "Infrared Physics Technology" and "Energy and Buildings" are authoritative in the field and are important platforms for publishing and communicating research results. In the authors' cocitation network, the academic relationship between authors is close, and X Maldague from Canada is more prominent, ranking high in the number of citations and article quality.

(2) The keyword "infrared thermography" in the co-occurrence and timeline view is not only the most frequent but also the keyword for all the periods of infrared detection technology research. By fitting the keywords to obtain five clusters, the core keywords of each cluster can be integrated to know that infrared detection technology is mainly used in nondestructive testing technology. The infrared camera is the main detection instrument, and its performance and the corresponding image processing technology are also driving forces for the research and development. Nondestructive testing between 2004 and 2008 emerged as a hotspot in the research of infrared detection technology, 
and thermal imaging image processing technology also appeared as a new research hot spot. In the past five years, vibration thermal imaging, pulse thermal imaging, photonic crystals, skin temperature, remote sensing technology and concrete delamination defect detection are prominent research hotspots.

(3) At present, infrared detection technology is widely applied and researched, but most studies remain at the qualitative level, that is, the information obtained by using infrared detection is combined with the tester's own experience to make a qualitative judgment as to whether there is a defect. Therefore, the gradual transformation from qualitative research methods to new quantitative methods, and gradually moving toward standardization is one of the important trends of infrared detection technology research. The requirements for online testing, automated testing and portable testing equipment will be higher and higher, and the testing system will be developed towards automation, portability and humanization. Therefore, engineering application research is also one of the important trends for infrared detection technology. In addition, the combination of five conventional detection technologies with infrared detection technology is also an important research trend. To better solve practical detection problems, a combination of multiple detection technologies and complementary advantage makes detection more efficient and accurate.

Author Contributions: The research was designed and performed by H.L., R.H. and C.X. The data were collected by C.X. and H.L. Analysis of data was performed by H.L., R.H., C.X., A.G. and W.P. Finally, the paper was written by R.H., C.X. and H.L. All authors read and approved the final manuscript.

Funding: This research was funded in part by the National Key R\&D Program of China (2017YFC0804900), the Natural Science Foundation of China (51804287), the Zhejiang Provincial Natural Science Foundation of China (LY14E040001), and the Program of Safety Production Key Technology for Prevention and Control of Serious and Major Accidents of Ministry of Emergency Management of China (zhejiang-0003-2018AQ).

Acknowledgments: The authors would like to convey their heartfelt gratefulness to the reviewers and the editor for the valuable suggestions and important comments which greatly helped them to improve the quality of this manuscript.

Conflicts of Interest: The authors declare no conflict of interest.

\section{References}

1. Wiecek, B. Review on thermal image processing for passive and active thermography. Int. Conf. Eng. Med. Biol. Soc. 2005, 1, 686-689.

2. Chen, C.H. Ultrasonic and Advanced Methods for Nondestructive Testing and Material Characterization; World Scientific: Singapore, 2007.

3. Chen, Y.S.; Hung, Y.; Ng, S.P.; Liu, L. Review and comparison of shearography and active thermography for nondestructive evaluation. Mater. Sci. Eng. R Rep. 2009, 64, 73-112.

4. He, Y.; Du, B.; Huang, S. Noncontact Electromagnetic Induction Excited Infrared Thermography for Photovoltaic Cells and Modules Inspection. IEEE Trans. Ind. Inf. 2018, 14, 5585-5593. [CrossRef]

5. Usamentiaga, R.; Venegas, P.; Guerediaga, J.; Vega, L.; Molleda, J.; Bulnes, F.G. Infrared Thermography for Temperature Measurement and Non-Destructive Testing. Sensors 2014, 14, 12305-12348. [CrossRef] [PubMed]

6. Gorostiza, E.M.; Galilea, J.L.; Meca, F.J.; Monzu, D.S.; Zapata, F.E.; Puerto, L.P. Infrared sensor system for mobile-robot positioning in intelligent spaces. Sensors 2011, 11, 5416-5438. [CrossRef] [PubMed]

7. Vadivambal, R.; Jayas, D.S. Applications of Thermal Imaging in Agriculture and Food Industry-A Review. Food Bioprocess Technol. 2011, 4, 186-199. [CrossRef]

8. Ciampa, F.; Mahmoodi, P.; Pinto, F.; Meo, M. Recent Advances in Active Infrared Thermography for Non-Destructive Testing of Aerospace Components. Sensors 2018, 18, 609. [CrossRef]

9. Liu, H.; Yu, Z.H.; Hong, R.; Jin, K.; Yang, C. Visualization and Bibliometric Analysis of Research Trends on Human Fatigue Assessment. J. Med. Syst. 2018, 42, 179. [CrossRef]

10. Figueiredo, A.A.A.; Fernandes, H.C.; Guimaraes, G. Experimental approach for breast cancer center estimation using infrared thermography. Infrared Phys. Technol. 2018, 95, 100-112. [CrossRef]

11. Abdel-Nasser, M.; Moreno, A.; Puig, D. Breast Cancer Detection in Thermal Infrared Images Using Representation Learning and Texture Analysis Methods. Electronics 2019, 8, 100. [CrossRef] 
12. Adam, M.; Ng, E.Y.K.; Tan, J.H.; Heng, M.L.; Tong, J.W.K.; Acharya, U.R. Computer aided diagnosis of diabetic foot using infrared thermography: A review. Comput. Biol. Med. 2017, 91, 326-336. [CrossRef] [PubMed]

13. Nguyen, A.V.; Cohen, N.J.; Lipman, H.; Brown, C.M.; Molinari, N.O.; Jackson, W.L.; Kirking, H.; Szymanowski, P.; Wilson, T.W.; Salhi, B.A.; et al. Comparison of 3 Infrared Thermal Detection Systems and Self-Report for Mass Fever Screening. Emerg. Infect. Dis. 2010, 16, 1710-1717. [CrossRef] [PubMed]

14. Vargas, J.V.C.; Brioschi, M.L.; Dias, F.G.; Parolin, M.B. Normalized methodology for medical infrared imaging. Infrared Phys. Technol. 2009, 52, 42-47. [CrossRef]

15. Manginas, A.; Andreanidis, E.; Leontiadis, E.; Sfyrakis, P.; Maounis, T.; Degiannis, D.; Alivizatos, P.A.; Cokkinos, D.V. First human application of right ventricular endocardial thermography in transplanted and coronary artery disease patients. J. Invasive Cardiol. 2010, 26, S224.

16. Jadin, M.S.; Taib, S. Recent progress in diagnosing the reliability of electrical equipment by using infrared thermography. Infrared Phys. Technol. 2012, 55, 236-245. [CrossRef]

17. Badulescu, C.; Grediac, M.; Haddadi, H.; Mathias, J.D. Applying the grid method and infrared thermography to investigate plastic deformation in aluminium multicrystal. Mech. Mater. 2011, 43, 36-53. [CrossRef]

18. Liu, H.; Wang, Z.; Zhong, J.; Xie, Z. Early detection of spontaneous combustion disaster of sulphide ore stockpile. Teh. Vjesn. 2015, 22, 1579-1587.

19. Ait-Amokhtar, H.; Fressengeas, C.; Boudrahem, S. The dynamics of Portevin-Le Chatelier bands in an Al-Mg alloy from infrared thermography. Mater. Sci. Eng. A 2008, 488, 540-546. [CrossRef]

20. Pastor, M.L.; Balandraud, X.; Grediac, M.; Robert, J.L. Applying infrared thermography to study the heating of 2024-T3 aluminium specimens under fatigue loading. Infrared Phys. Technol. 2008, 51, 505-515. [CrossRef]

21. Glowacz, A.; Glowacz, Z. Diagnosis of the three-phase induction motor using thermal imaging. Infrared Phys. Technol. 2017, 81, 7-16. [CrossRef]

22. Glowacz, A.; Glowacz, Z. Diagnostics of stator faults of the single-phase induction motor using thermal images, MoASoS and selected classifiers. Measurement 2016, 93, 86-93. [CrossRef]

23. Kafieh, R.; Lotfi, T.; Amirfattahi, R. Automatic detection of defects on polyethylene pipe welding using thermal infrared imaging. Infrared Phys. Technol. 2011, 54, 317-325. [CrossRef]

24. Balaras, C.A.; Argiriou, A.A. Infrared thermography for building diagnostics. Energy Build. 2002, 34, 171-183. [CrossRef]

25. Nardi, I.; Lucchi, E.; Rubeis, T.; Ambrosini, D. Quantification of heat energy losses through the building envelope: A state-of-the-art analysis with critical and comprehensive review on infrared thermography. Build. Env. 2018, 146, 190-205. [CrossRef]

26. Lerma, J.L.; Cabrelles, M.; Portales, C. Multitemporal thermal analysis to detect moisture on a building facade. Constr. Build. Mater. 2011, 25, 2190-2197. [CrossRef]

27. Van Eck, N.J.; Waltman, L. Software survey: VOSviewer, a computer program for bibliometric mapping. Scientometrics 2010, 84, 523-538. [CrossRef] [PubMed]

28. Chen, C.; Hu, Z.; Liu, S.; Tseng, H. Emerging trends in regenerative medicine: A scientometric analysis in CiteSpace. Expert Opin. Biol. 2012, 12, 593-608. [CrossRef] [PubMed]

29. Jan van Eck, N.; Waltman, L. VOS: A New Method for Visualizing Similarities Between Objects. Adv. Data Anal. 2006, 299-306.

30. Rogalski, A. Infrare detectors: Status and trends. Prog. Quantum Electron. 2003, 27, 59-210. [CrossRef]

31. Bruck, H.A.; Rosakis, A.J.; Johnson, W.L. The dynamic compressive behavior of beryllium bearing bulk metallic glasses. J. Mater. Res. 1996, 11, 503-511. [CrossRef]

32. Jones, B.F. A reappraisal of the use of infrared thermal image analysis in medicine. IEEE Trans. Med. Imaging 1998, 17, 1019-1027. [CrossRef] [PubMed]

33. Senkan, S.M. High-throughput screening of solid-state catalyst libraries. Nature 1998, 394, 350-353. [CrossRef]

34. Lahiri, B.B.; Bagavathiappan, S.; Jayakumar, T.; Philip, J. Medical applications of infrared thermography: A review. Infrared Phys. Technol. 2012, 55, 221-235. [CrossRef]

35. Zhu, J.; Hua, W. Visualizing the knowledge domain of sustainable development research between 1987 and 2015: A bibliometric analysis. Scientometrics 2017, 110, 893-914. [CrossRef]

36. De Salis, A.F.; Saatchi, R.; Dimitri, P. Evaluation of high resolution thermal imaging to determine the effect of vertebral fractures on associated skin surface temperature in children with osteogenesis imperfecta. Med. Biol. Eng. Comput. 2018, 56, 1633-1643. [CrossRef] [PubMed] 
37. Mohammadi, F.; Rastgar-Jazi, M. Analytical and Experimental Solution for Heat Source Located Under Skin: Modeling Chest Tumor Detection in Male Subjects by Infrared Thermography. J. Med. Biol. Eng. 2018, 38, 316-324. [CrossRef]

38. Mayilsamy, S.; Jeyakumar, S.; Manimaran, A.; Pushpadass, H.A. Infrared thermography to monitor body and udder skin surface temperature differences in relation to subclinical and clinical mastitis condition in Karan Fries (Bos taurus $\times$ Bos indicus) crossbred cows. Indian J. Anim. Sci. 2018, 88, 694-699.

39. Pou, A.; Diago, M.P.; Medrano, H.; Baluja, J.; Tardaguila, J. Validation of thermal indices for water status identification in grapevine. Agric. Water Manag. 2014, 134, 60-72. [CrossRef]

40. Kordatos, E.Z.; Dassios, K.G.; Aggelis, D.G.; Matikas, T.E. Rapid evaluation of the fatigue limit in composites using infrared lock-in thermography and acoustic emission. Mech. Res. Commun. 2013, 54, 14-20. [CrossRef]

41. Milne, J.M.; Reynolds, W.N. The Non-Destructive Evaluation of Composites and other Materials by Thermal Pulse Video Thermography. In Proceedings of the Thermosense VII: Thermal Infrared Sensing for Diagnostics and Control, Cambridge, MA, USA, 23-26 October 1984; pp. 119-123.

42. Busse, G.; Wu, D.; Karpen, W. Thermal wave imaging with phase sensitive modulated thermography. J. Appl. Phys. 1992, 71, 3962-3965. [CrossRef]

43. Maldague, X.; Marinetti, S. Pulse phase infrared thermography. J. Appl. Phys. 1996, 79, 2694-2698. [CrossRef]

44. Favro, L.D.; Han, X.; Ouyang, Z.; Sun, G.; Sui, H.; Thomas, R.L. Infrared imaging of defects heated by a sonic pulse. Rev. Sci. Instrum. 2000, 71, 2418-2421. [CrossRef]

45. Cheng, C.C.; Cheng, T.M.; Chiang, C.H. Defect detection of concrete structures using both infrared thermography and elastic waves. Autom. Constr. 2009, 18, 87-92. [CrossRef]

46. Kreidberg, L.; Line, M.R.; Bean, J.L.; Stevenson, K.B.J.; Désert, J.-M.; Madhusudhan, N.; Fortney, J.J.; Barstow, J.K.; Henry, G.W.; Williamson, M.H. A detection of water in the transmission spectrum of the hot jupiter wasp-12b and implications for its atmospheric composition. Astrophys. J. 2015, 814, 66. [CrossRef]

47. Montinaro, N.; Cerniglia, D.; Pitarresi, G. A Numerical Study on Interlaminar Defects Characterization in Fibre Metal Laminates with Flying Laser Spot Thermography. J. Nondestruct. Eval. 2018, 37, 41. [CrossRef]

48. Tran, H.Q.; Huh, J.; Mac, H.V.; Kang, C. Effects of rebars on the detectability of subsurface defects in concrete bridges using square pulse thermography. Ndt E Int. 2018, 100, 92-100. [CrossRef]

49. Carslaw, H.S.; Jaeger, J.C. Conduction Heat in Solids. Math. Gaz. 1959, 36, 142-143. [CrossRef]

50. Maldague, P.F. Many-body corrections to the polarizability of the two-dimensional electron gas. Surf. Sci. 1978, 73, 296-302. [CrossRef] 